\begin{tabular}{c} 
Volume and Issues Obtainable at Center for Sustainability Research and Consultancy \\
Journal of Business and Social Review in Emerging Economies \\
ISSN: 2519-089X (E): 2519-0326 \\
Volume 6: Issue 2 June 2020 \\
JSRᄃ \\
Journal homepage: www.publishing.globalcsrc.org/jbsee \\
\hline
\end{tabular}

\title{
Impact of Violent Cartoons on the Behaviour of Children: A Case Study of South Punjab ${ }^{1}$ Tahir Mahmood, ${ }^{2}$ Urwah Iftikhar, ${ }^{3}$ Muhammad Ahsan Bhatti
}

${ }^{1}$ Assistant Professor, Department of Communication Studies, Bahauddin Zakariya University, Multan, Pakistan, tahirmahmood@bzu.edu.pk

${ }^{2}$ Lecturer, Department of Mass Communication, Lahore College for Women University(LCWU), Lahore,Pakistan,arwah.iftikhar@hotmail.com

${ }^{3}$ Assistant Professor, Department of Communication Studies, Bahauddin Zakariya University, Multan, Pakistan, Ahsanbhatti@bzu.edu.pk

\begin{tabular}{l}
\hline \multicolumn{1}{c}{ ARTICLE DETAILS } \\
\hline History \\
Revised format: May 2020 \\
Available Online: Jun 2020 \\
Keywords \\
$\begin{array}{l}\text { Cartoon, TV Violence, } \\
\text { Children, behavior, South } \\
\text { Punjab, fear }\end{array}$ \\
\hline
\end{tabular}

JEL Classification

H83, M41

\begin{abstract}
Basically, this is a survey research that investigates the impact of violent cartoons on the behaviour of children. Children often draw strong social or anti-social ideas from children's movies and cartoons. Television is the most popular medium in which the children are exposed. The media is constantly creating new cartoons with increased violence and children do not realize how harmful this is to them. The study investigates that how children are being exposed to anti-social content and what impact is done on their behavior. Cartoons have much value in personality construction of children especially in very early age. Children try to become like their favorite cartoon character. They try to mimic and copy the actions performed by their favorite cartoon hero. The environment in which the children watch horror or violent cartoons is also very important. They may develop fears or antisocial behavior in the absence of parental guidance.
\end{abstract}

(C) 2020 The authors, under a Creative Commons AttributionNonCommercial 4.0

Corresponding author's email address: Ahsanbhatti@bzu.edu.pk

Recommended citation: Mahmood, T., \& Iftikhar, U., \& Bhatti, M. A., (2020). Impact of Violent Cartoons on the Behaviour of Children :A Case Study of South Punjab. Journal of Business and Social Review in Emerging Economies, 6 (2), 689-702

\section{Introduction}

Rashid (2015) found that watching cartoons has become popular among the children around the world. But it is found that the content shown in cartoons have a subtle, but consistent effect on them.these effects have some positive impacts on the children and adverse impacts as well. A lot of researches have found that behaviour of children changes as they watch violent cartoon shows. On the other hand it is also observed that educative and informative cartoon content enhances imagination and creativity among the children. Language also plays an important role to effect the children. If the language of cartoon 
show is understandable and comprehend-able for the children, they enjoy it more and get involved in the cartoon show. This involvement is reflected in their behavior as well.

There are different types of effects.

1. Physical effects

2. Emotional effects

3. Cognitive effects

4. Behavioral effect

\subsection{Physical Effects}

Rashid (2015) found that The physical effects of watching TV is not more observed on behaviour of children. Because TV need no special force exerted when it compare with reading habit. But the force exerted become more effective when the children are sitting more close to screen to watching their favourite cartoon. If they watch TV for significantly long period of time, then it may also harm their physical health as well. This extensive TV watching habit and poor light condition may also affect their sleep.

\subsection{Emotional Effects}

Habib \& Tarek (2015) observed that Emotional effects of TV were harmless as TV program creates more fear among the kids. Raza, Awan and Gondal (2016) found that if children start to watch all these types of programs in very early age they consider everything real and become more affected by the content. If they watched TV alone and in a dark room, it become more harmful for them because they may develop fears and insecurities.

\subsection{Cognitive Effects}

Shaffer (2007) found that TV program played a dynamic role in mental evolution of children. This was more destructive for children who learned some real experiences from that content. Children are not mentally so mature that they could differentiate between reality and fantasy. This thing affect their cognition and they start living in a fantasy world. The children who watch TV alone and programs with a fantasy construction may make children wish that everything in this world be like a fantasy world.

\subsection{Behavioural Effects}

Krish (2006) found that TV programs specially action cartoons can develop violent behaviour in children. They could not realize the difference between the ground realities and rules of real world and fantasy. They may learn aggression from fantasy world and make its contrivance in real world. They want to act like a popular character of a fantasy story, Deserting the difference between good and bad characters.

Merriam-Webster (2020) defined violence as use of physical force to injure, abuse, damage, or destroy. This may be done to any person, group or community at large. The state or quality of being violent is highly excited action, whether physical or moral. In simple words we can say that it is a broader sense to include behavior by people or against people liable to cause physical or psychological harm. Krug et al. (2002) found that the World Health Organization has divided the violence into three broad categories:

- $\quad$ self-directed violence

- interpersonal violence

- collective violence

These three categories were farther elaborated into four types of violence 
- physical

- sexual

- psychological

- emotional

Hassan \& Daniyal (2013) found that for over 80 years television shows and animated films have been entertaining kids and adults. In 1920s the first true animated star was feline icon Felix the Cat. Felix was also the first animated character to be heavily goods to be bought and sold to the American public, with watches, toys, baby oil, dolls and cigars bearing his likeness. Soon, Walt and Roy Disney launched the Disney Brothers cartoon studios. Klien (1993) found that by the early 1930's ,characters such as Donald Duck, Mickey Mouse and Pluto were making their position onto the silver screen and got international popularity in a cartoon series called Silly Symphonies. The historical fame of animated movies cannot be the state less than the truth about. From the start, animated movies were got box office popularity. As information, consider the following: the Seven Dwarfs is still one of the top ten grossing films of all time. Some 70 years later, still animated films as popular as ever. For example, 2004 DreamWorks animated film Shrek 2 generated nearly $\$ 900$ million in box office being received and millions more in DVD sales.

Johnson (2014) observed that In the mid-1950s, the violence carrying a lot Popeye the sailor dominated the airways, generating millions of dollars in advertising revenue. Due to the success of Popeye, many studios such as Hanna Barbera began to produce TV animated series and in 1960 the first cartoon The Flintstones became to air during prime time hours (8:00-11:00). A piece of cartoon series soon followed, with shows such as Jonny Quest, Speed Racer, Rockey Bullwinkle and Scooby Doo Mysteries generating a large viewership among children. Now a days new television series and animated film classics can be seen on cable channels such as Cartoon network, Boomerang and The Disney channel.

Velikovsky (2012) found that Tex Avery is creating Droopy Dog, Daffy Duck, and, most importantly, Bugs Bunny. Chuck Jones was one of the greatest animators, writers, producers, and directors for Looney Tunes and Merrie Melodies. Since the inception of animation, violence has been always a part of cartoon content. That may be comedic or dramatic form, there is a large amount of violence is in cartoons than in other types of programming. Krish (2006) found that a little known reality is the children and adolescents are more likely to witness acts of media draws violence during Saturday morning cartoons than during prime time television hours.

Krish (2006) also observed that, there is lots of difference between dramatic cartoons and violent cartoons. Violent cartoons which are shown on TV tend to involve minor acts of violence, death is rarely animated and rape scenes are never televised. The pain and suffering of the victim is often highlighted, the victims are rarely shown who are suffering in realistic pain, the difference, prime time dramas regularly involve major acts of violence. Although the term cartoons connote the presence of action elements, not all cartoons portray comedy there is also having involvement of action context. Mostly cartoons portray violence in the cartoons like Batman, Ben10, Sumarai Jack etc.

Nair (2018) found that action cartoon create change in the behaviour of the children, because they like that character and want to look like that character and this change becomes irritating for their parents and also for peer groups. The study also found that youngsters tended to imitate the negative behaviour they saw on TV such as a piece of a story passed from person to person, which may not be true, gossiping and eye-rolling. Children as young as seven, which included a number of cartoons, had the greatest levels of violence. Anderson, Gentile \& Buckley (2008) observed that in fact, even cartoonish children's games increase aggression in their behaviour. Certain types of media violence as "fantasy" violence is misleading the children and may really serve to increase children's access to harmful violent content by reducing parental concern.

\section{Significance of the Study}


The researcher is working on "The impact of violent cartoons on the behaviour of the children" because the cartoons have much value in character building of kids. Children start watching cartoons at the age of two year and from the age of 2 to 11 year they expended more time in front of television watching their favourite contented then the time they have passed in school. Thus the cartoon programs are much operative the school lessons. Sometime children's sensation themselves like cartoon characters. This is because they like them much and it is wildlife that with whom you are impressed you adopt some feature of his character likewise children also adopt some habits from cartoons characters and when they elite their characteristics they become part of their personality. Now this new personality is positive or negative? Why they adopt their characteristics?

Why they behave like the characters of the cartoons, when they start to impress from those personalities. Which content impress them and what influence those characters leave in the personality of children. This is all about my study.

\section{Statement of the Problem}

Mahsud, Rawan, \& Normn (2009) establish in one study, preschool children were observed both before and after watching television; some watched cartoons that had many aggressive and violent acts; others watched shows that didn't have any kind of violence. Children who watched the violent shows were more likely to strike out at playmates, argue, disobey authority and were less willing to wait for things than those children who watched non-violent programs.

Raza, Abu baker \& Mohamad (2019) found that in today's society, electronic media is methodically combined into the fabric of life, with television, movies, videos, music, advertising, video games, and computers crucial to both work and play. Recent studies designate that even the youngest children are using a wide variety of screen media, many at advanced levels than suggested by child development professionals.

There are quickly growing markets for early children television programming, computer software for kids, and video series for children. This research project is meant to find out what are the effects of violent cartoons character on the personality and the dealing of the children with their friends and their family members as well.

\section{Objectives of the study}

1: To study the role of cartoons in making aggressive behaviour of children.

2: To check out that violent cartoons are leading the children towards immoral acts.

3: To investigate whether cartoons are creating sense of fear among children.

\section{Literature}

Daven et al (1976) wanted to investigate and provided his research of cartoon and its impact on Society. These results were set to give readers a clear acquaintance to the cartoon world and its Impact on the society as delicate issue. Each topic covered both the important aspects of its robust. Substantive examinations supported by observational evidence and case study. The researcher has also shown that cartoons are shown as a positive source of learning. The world of cartoon has indirectly changed children's action towards the world and made them grow as an individual. Cartoons bring children's lives to life in a fictional world.

Fouts, Callen and Lawson (2006) television and movies are the two main media used by young Children that are the success of demonization. There are two content analyses that have been done Using animated feature films $(n=34)$ of the Walt Disney company and after school cartoons $(n=41)$ Each was tacit for the demonstration of the use of "evil" words when talk to a person, e.g., Monster, devil, demon, wicked Seventy-four per cent of Disney films retain "wicked" references, with an average of 5.6 
references per film. Forty four percent of the after-school kids show retain "wicked" references, with an average of one per animation. The outcomes are discussed about the situation of children's repeated exposure to successful movies and cartoons and their learning to demonize people who are engaged in awareness of bad conduct.

Bandura, Ross and Ross (1963) studied and compare the impact of T.V and cartoon violence and Realworld violence on kids. They conduct an experiment and divide 100 school kids into four groups. The primary group gather and observed a genuine yell insuperable at an inflatable whereas hitting it with a little wooden pond. The other bunch observed the same occurrence on the television. The third observed the cartoon adaption of the same scene and forth bunch gather nothing because they observe nothing. When all the children were subsequently supervised in a baffling situation the Primary three bunches seemed more animosity than control group. The kids who observed the Occurrence on TV alter the conduct of the children which was hostility as those who had observed the genuine individual utilize the wooden pound and both were more forceful than those who had observed the cartoon.

Scharrer (2006) found that the analyst turned to the research center and compares the behavior of 24 children watching TV. Half of them observed the rough scene of the cartoon Woody Woodpecker and the other 12 observed the nonviolent scene of The Little Red Hen. In the midst of playing a little later, The analyst looked at the children who saw rough cartoons hitting the other kids and breaking toys

Seck (2007) found that Singer, Slovak, Fireson and York surveyed in 1998. They conduct study on 856 grade three students living in a semi-rural community in Columbia Country, New York and found that those kids who observed wild Cartoons in their home they carry on more violent in school. Eron wants to follow the impact of this introduction during the year, so in 1971 he returned to Columbia Country, when the kids who took interest within the 1960 study were 19 years old he get outcome that boys who observed rough TV shows at the age of 8 more likely to urge inconvenience with the law as young.

Singer et al. (1998) interviewed 2000 Ohio students in grade three to eight. They announce that the occurrence of psychological shocks mental and emotional misery and uneasiness that expanded in extent to the number of hours by observing TV daily. Anderson and Carnagey (2004) sum up that the savagery draws in TV programs, especially cartoons incorporates a exceptionally negative affect on the conduct of children. However, young children may be less incline to undertake difficult to break even with savage activity seen on TV than thought. Analyst demonstrates that youthful children have restricted control of understanding of TV substance but moderately having a extraordinary bargain of involvement or advanced ethical thinking. Children's understanding of the evil of viciousness on TV and the contrast between substances and make accept intervene these impacts, as may the comedian viewpoint of cartoons they see. We audit the current investigate which is concerned to the impacts of cartoon Savagery on children's ethical understanding and their conduct to with the objective of making a difference early childhood teachers and almost children's tv seeing guardians make educated choices.

Greenberg \& Reeves(1976) explore the effect of television and conduct an experiment in three Communities . They found that TV is exceptionally awesome and children who watch only violence on TV are inclined to be more violent. There is an other factor that helps in developing violent behavior is less IQ level. The children with less IQ and from poorer families are more vulnerable to behave violent after watching violence on TV. The relationship between TV viewing and other factors are more important to consider while studying the impact of TV content on the children.

Kaye \& Sapolsky (2004) found that just for the sake of fun, more and more kids are getting harmed and the number will continue to increase if remained unchecked. Balanced coverage of Animation World Network is the reason that a study of negative impacts of cartoons on kids is getting published and it is possible that parents and caretakers of kids might get shocked and depressed after seeing the results. But it is highly recommended that a positive attitude should be shown so that harmful cartoons could be banned. 
Clara and Marian (1980) took a Case study to observe the impacts of cartoons on children free play behavior. They took a sample of 65 children and 18 teachers who were also observed by researchers and kindergarten teachers. Children were asked four questions each.

1- Which TV program do they like?

2- Which cartoon program do they like the most?

3- Which are their favorite cartoons characters?

4- Why do they like those particular characters?

After that, their outdoor gaming behavior was observed by them. Similarly they asked a few questions from the teachers as well.

1- Have they observed any evidence from classroom that proved the impact of cartoons on kids?

2- Do they know about the favorite program of kids?

Results were drawn which stated that cartoons are most liked by kids and the cartoons program which are broadcasted at afternoon of weekdays. Teachers claimed that behavior of their students in the classroom is similar to that of television programs and practices shown in them.

Gentile \& Anderson (2006) found that video games and other television programs that practice violence in their content will contribute in increasing the aggressive and inappropriate behavior of kids on longterm basis. Raza, Abu baker \& Mohamad (2018) observed that television contents are acceptable in culture of any country but contents from which the children are being exposed need to be taken more carefully.

Ginmann et al (2003) observed that in social communication research, it is now revealed that animations also serve a different purpose. They are used to spread the word and make people aware of the message that needs to be addressed just like in marketing. Gunter \& Gunter (2019) observed that there are various reasons to affect the liking and avoiding certain TV characters according to their genders. Their physical appearance, costumes and gadgets, age, intelligence and over attitudes like goodness and badness in character plays a important role.

\section{Research Question and Hypothesis}

RQ1: Do the cartoons create sense of fear among children.

Hypothesis

H1: It is likely to be that violent cartoons makes behaviour of children aggressive.

$\mathrm{H} 2$ : It is likely to be that violent cartoons do not lead the children towards immoral acts.

\section{Research Methodology}

Humans are always curious to know about things places and the secrets which they do not know much about this human instinct is also regarded as the power which ensures that the human race continues the evaluation process in running of the societies so that a growth and advancement together with a continuous change is observed. All such changes undergo a rigorous research process before an acceptance is seen by the societies at large.

\subsection{Research Design}

This particular study chooses survey method as a research design. And quantitative method of data collection is used. Quantitative data is the information in the form of numbers. 


\subsection{Questionnaire}

To obtain basic data for hypothesis testing, researcher used survey method and a questionnaire was formulated for this purpose. The structured questionnaire comprises of mostly closed ended questions with a few questions having an option of other with specification has been used to get the basic information has been used to get the basic information and opinion of sample. The questionnaire has been used as a tool of data collection.

\subsection{Survey Research}

"Quantitative social research in which one systematically asks many people the some question then records and analyses their answers".

The study uses both descriptive and analytical methods to address the stated research aims descriptive surveys or studies also serve as direct sources of valuable knowledge concerning human behaviour. Descriptive studies are helpful for planning various educational programs. This study also benefits from this method.

\subsection{Universe of the Study}

"The broad class of units that are covered in a hypothesis. All the units to which the findings of a specific study might be generalized."

In this study the researcher select the primary school of Multan as the universe of the study.

\subsection{Population}

"The name for the large general group of many cases from which a researcher draws a sample and which is usually stated in theoretical terms".

The convenient sample consists of primary school of Multan, the school included 100 students and 100 parents, which is appropriate sample size.

\subsection{Sampling}

Convenient sampling teaching is used to select the primary school in south Punjab.

\section{Data Analysis}

Both qualitative and quantitative techniques have been used to analyse information gathered in the survey. A description of the gathered data set is presented both in tabulated and chart form.

\subsection{Description of the Data Set}

As mentioned in section researcher has used the survey method with the help of comprehensive questionnaire. The purposive sample consists of 200 respondents which is statically appropriate sample size. As reflected from some of observations below, the sample is characterized with a number of features which are a very close, representation of the population.

\section{Results}


Chart 1: Showing the Choice of Children about the Content of Cartoon Show

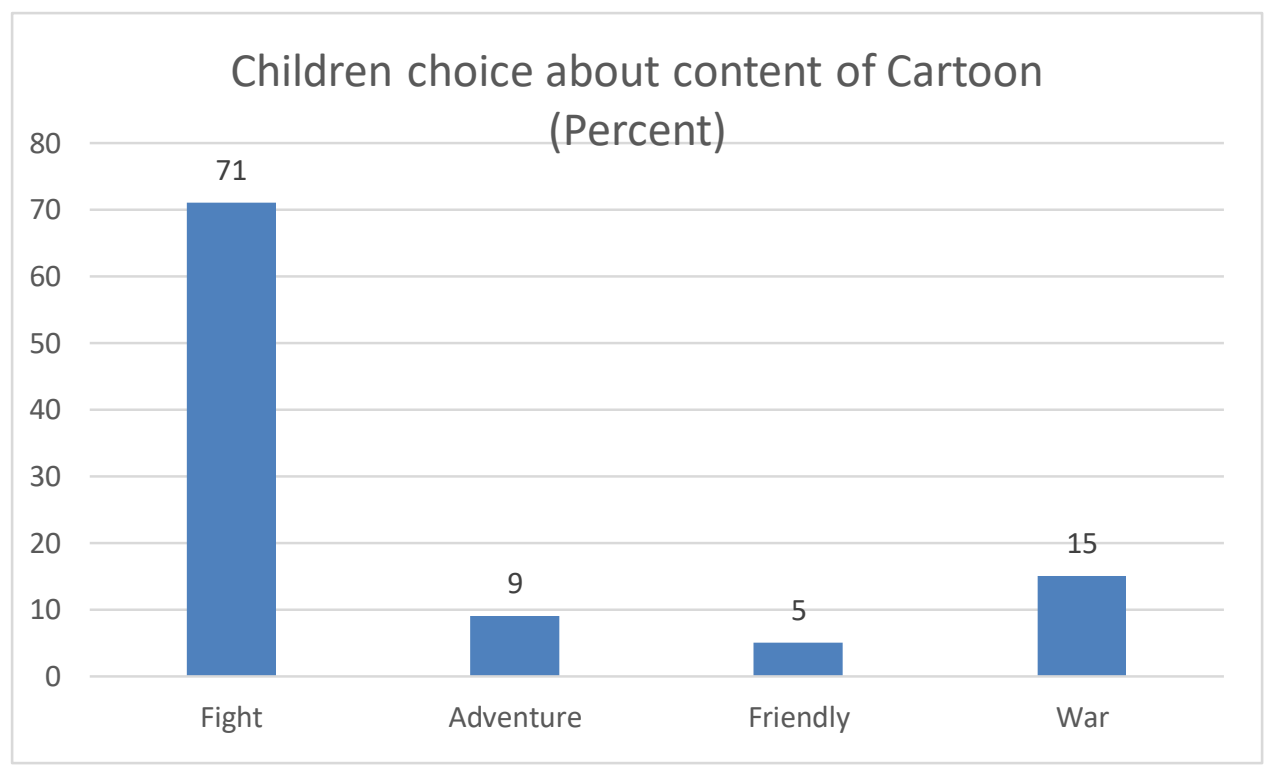

The frequency analysis shows that $71 \%$ children want the fight in the story of cartoon show. The children want the content of war in a cartoon show are 15\%. the collectively make 86\% (See chart:1), who want some sort of fight or war between persons or groups in a cartoon show. On the other hand only $9 \%$ children want the element of adventure in the cartoon and just $5 \%$ children preferred cartoon of a friendly nature.

Chart 2: Showing the Kind of fight liked by Children in a cartoon Show

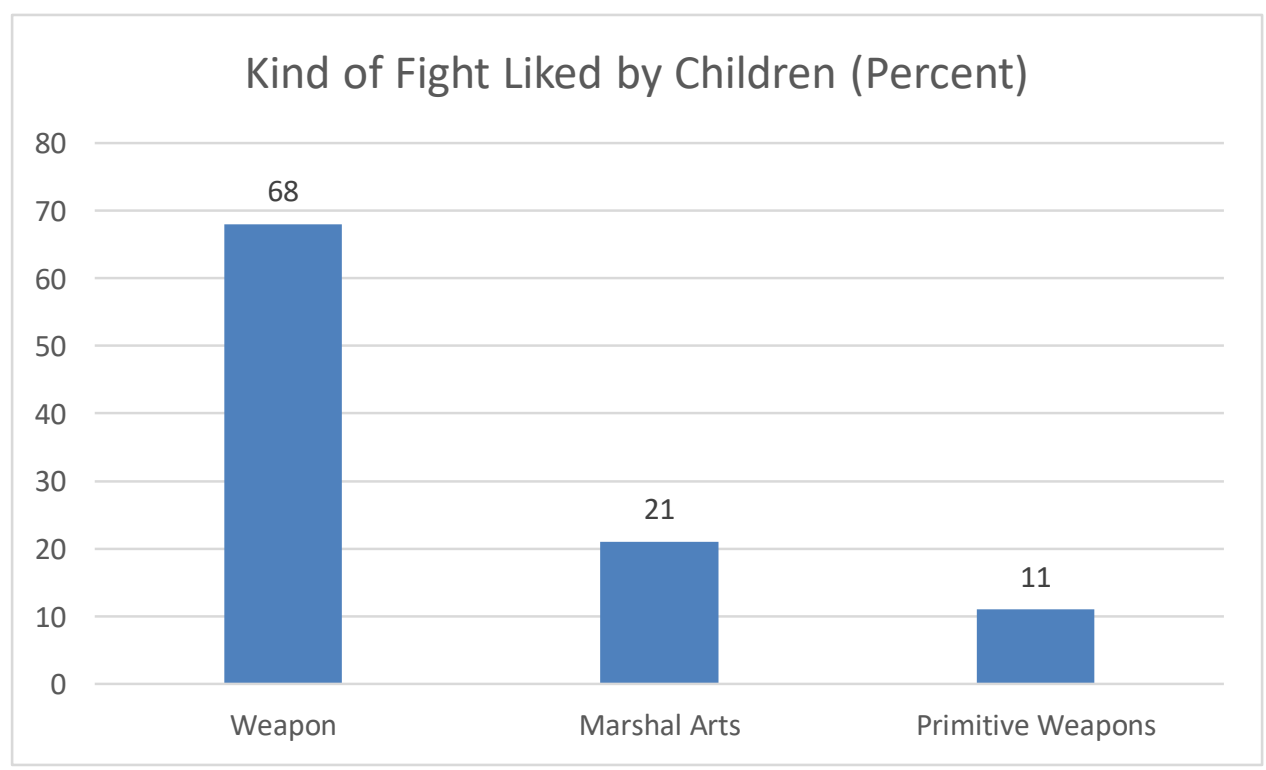

The frequency analysis shows that $68 \%$ children who want the content of fight or war in the cartoon show, want the fight with weapons. $21 \%$ children want the fight to be fought with a marshal arts (Kung $\mathrm{Fu}$, Judo, Karate etc). $11 \%$ of those children who want fight in the cartoon, want the fight with primitive weapons like sword, crossbow etc. 
Chart 3: Showing whether the Children Want to Fight Like Their cartoon Heroes

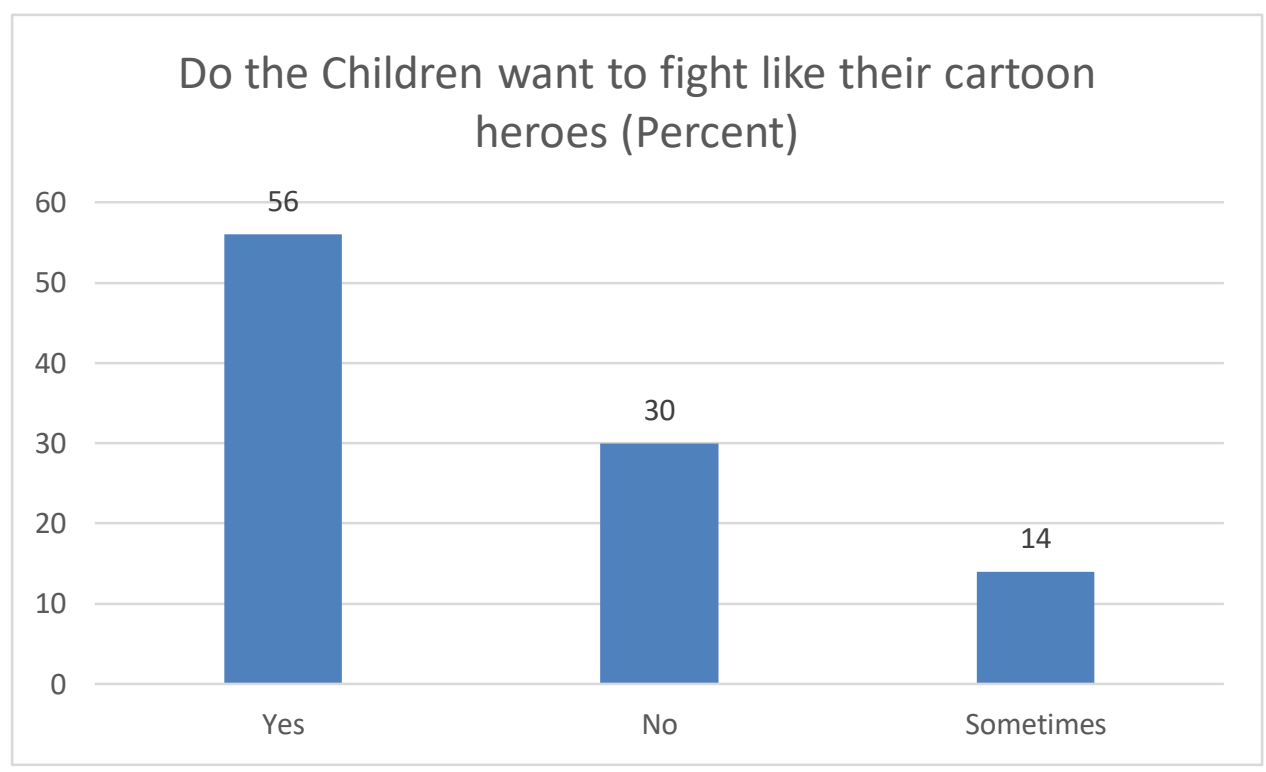

Frequency analysis show that $56 \%$ of the children who like fighting/action cartoon, like to fight like their super heroes. Among those children who like action cartoons , 30\% do not want to fight like the heroes of cartoon shows. On the other hand $14 \%$ children want to fight like their super heroes occasionally. Overall, it makes $70 \%$ children who like to fight like they watch in cartoon shows on some time or another (See chart :3)

Chart 4: Showing whether the Children watch Cartoon Show alone or with Family

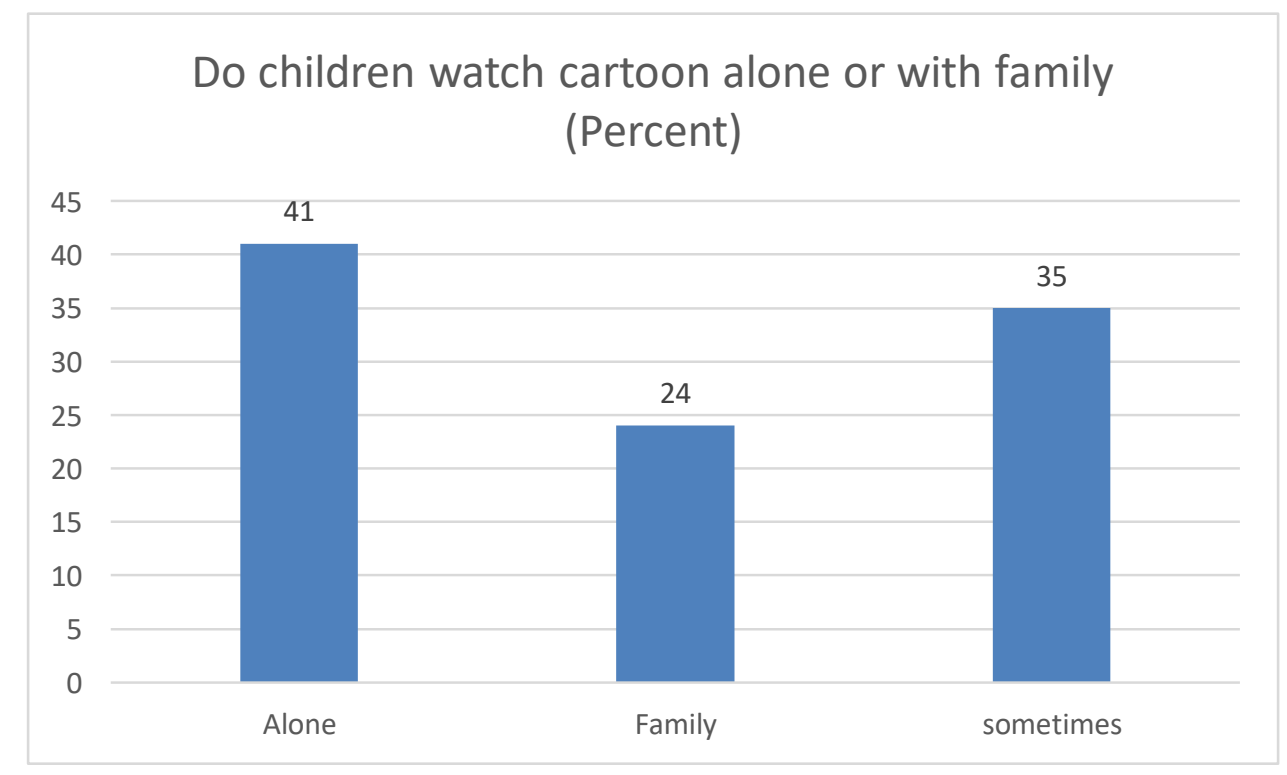

The frequency analysis shows that $41 \%$ of all children watch cartoon shows alone in the room. $35 \%$ children watch the cartoon when family members are around, wither they are sitting with them or roaming around. On the other hand $24 \%$ of children watch cartoon with their family members. 
Chart 5: Showing whether parents Guide the Children about the Content of Cartoon Show

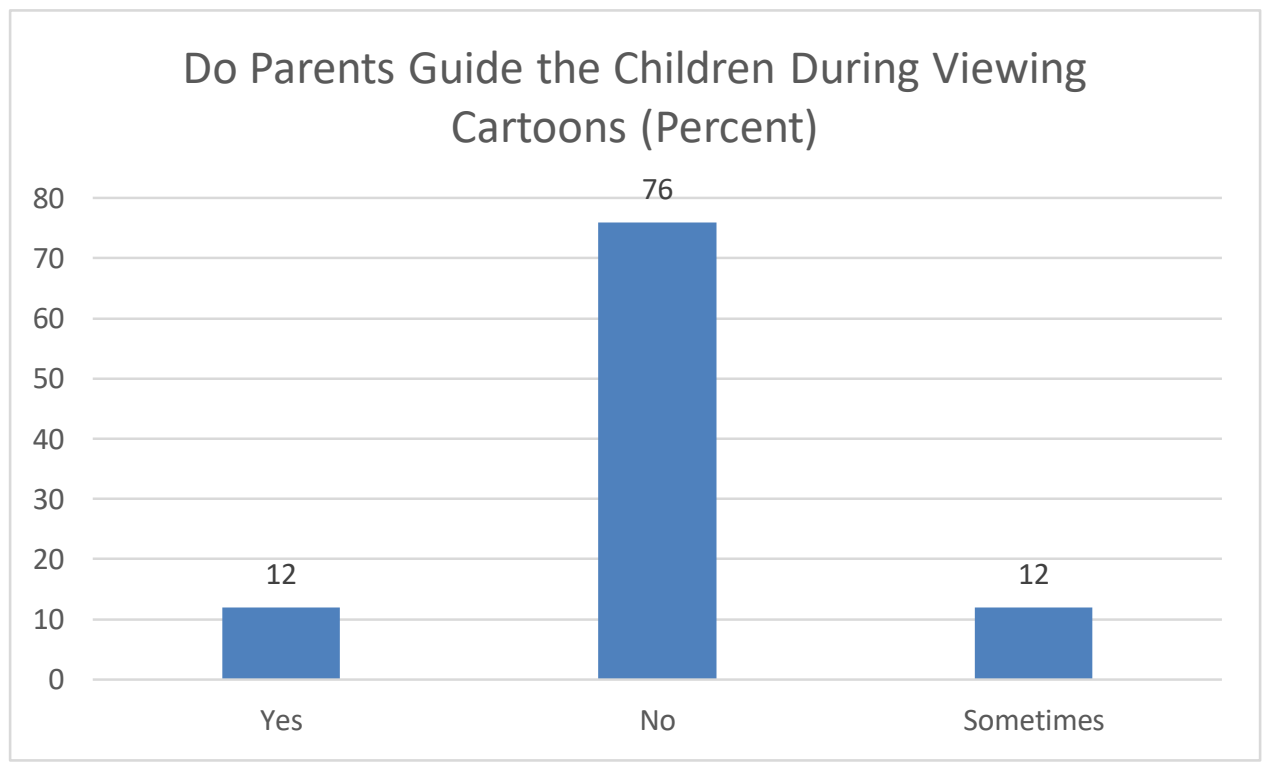

Frequency analysis shows that $76 \%$ of the children do not get any king of guidance of counselling about the contents of cartoon shows. Children watch and consume the content according to their own knowledge and perception. $12 \%$ of the children gets some guidance occasionally and $12 \%$ children do not get any guidance of counselling at all.

Chart 6: Showing Whether Children feel Fear after Watching Horror Cartoon Show

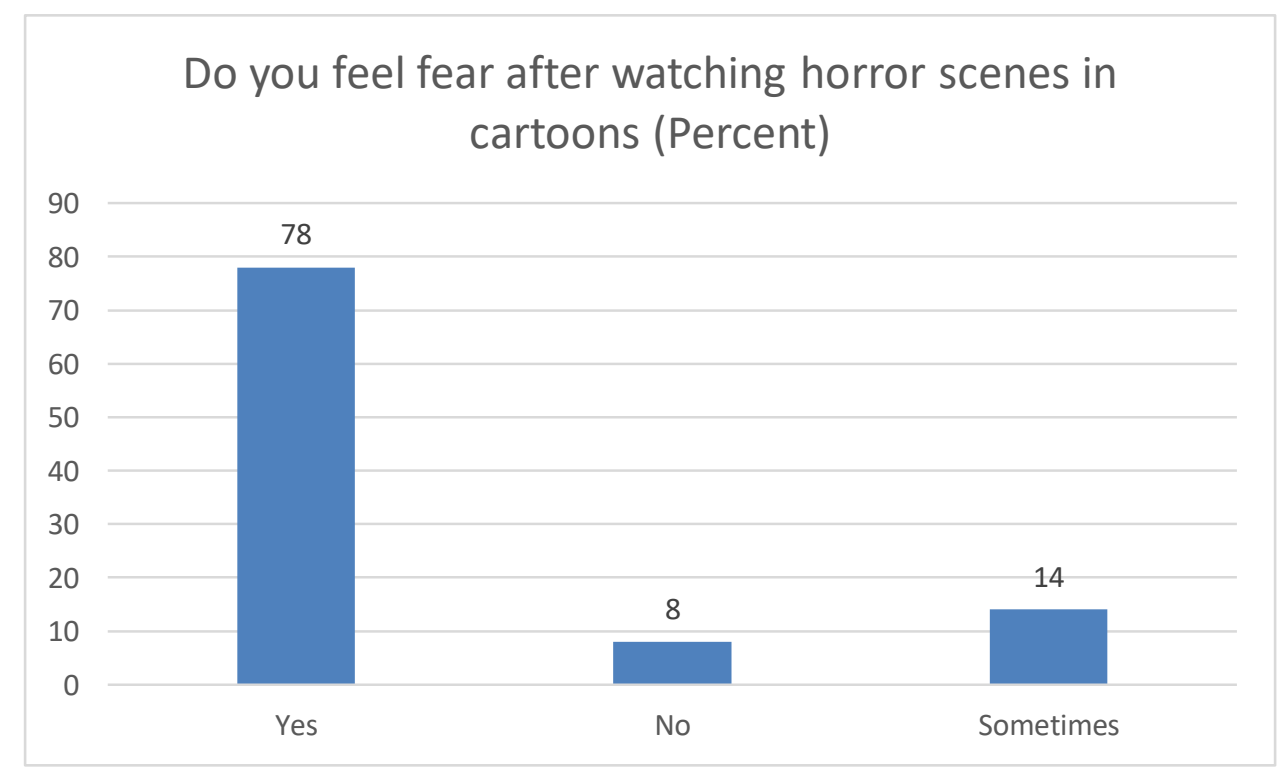

Frequency analysis shows that $78 \%$ of children feel fear when they go to some dark or alone places after watching horror cartoon shows. Only $8 \%$ of children responded that they don not feel any fear after watching the horror cartoon shows. On the other hand $14 \%$ of children feel fear occasionally after watching the horror contents of cartoon shows. 
Chart 7: Showing Whether Children think that Killing, Destroying and Damaging the enemy is acceptable

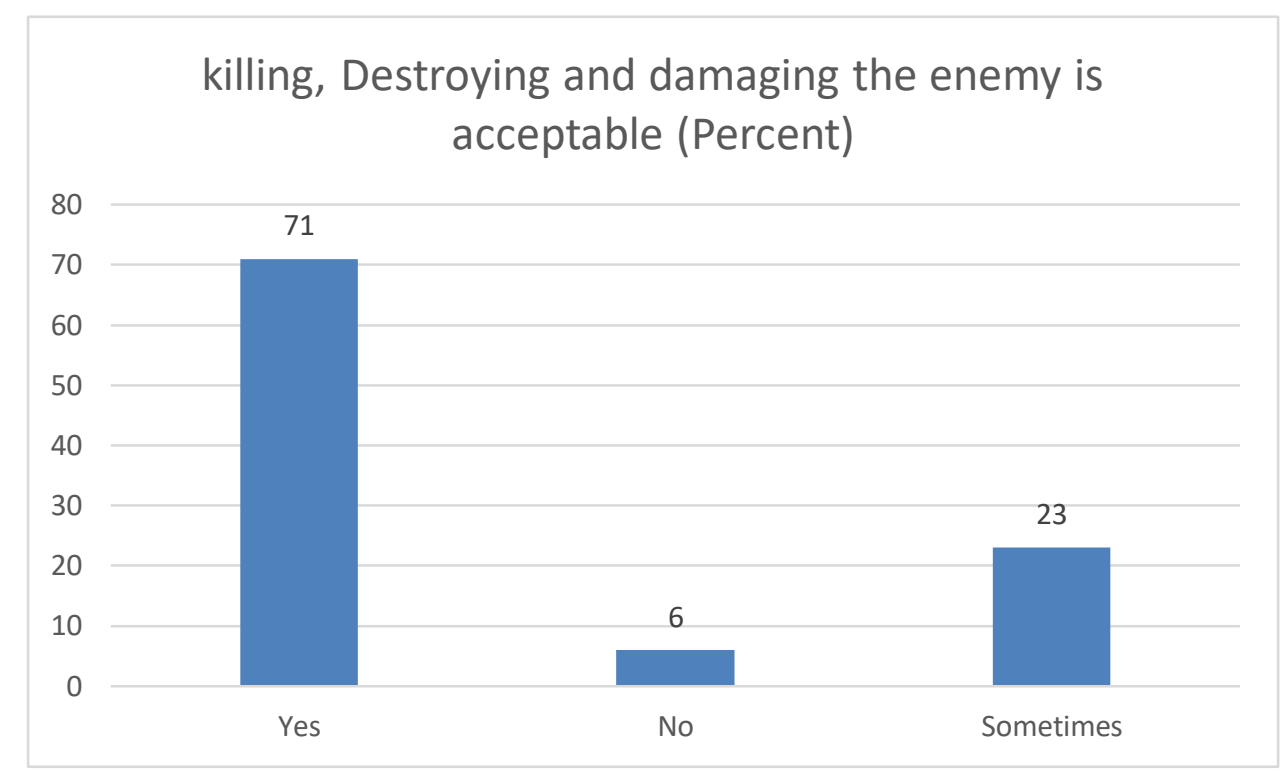

Frequency analysis shows that among those children who watch violent contents of cartoon shows, $71 \%$ children think that killing, destroying, damaging the enemy is righteous. Among these children, $23 \%$ think that killing, destroying and damaging the enemy is correct in some situations. Collectively it makes 94\%, who think these types of anti-social actions are legitimized in some way or another. On the other hand just $6 \%$ children think that killing, destroying or damaging the enemy is not righteous.

Chart 8: Showing Whether Parents Observed Their Children Copying/Mimicking the Cartoon Characters

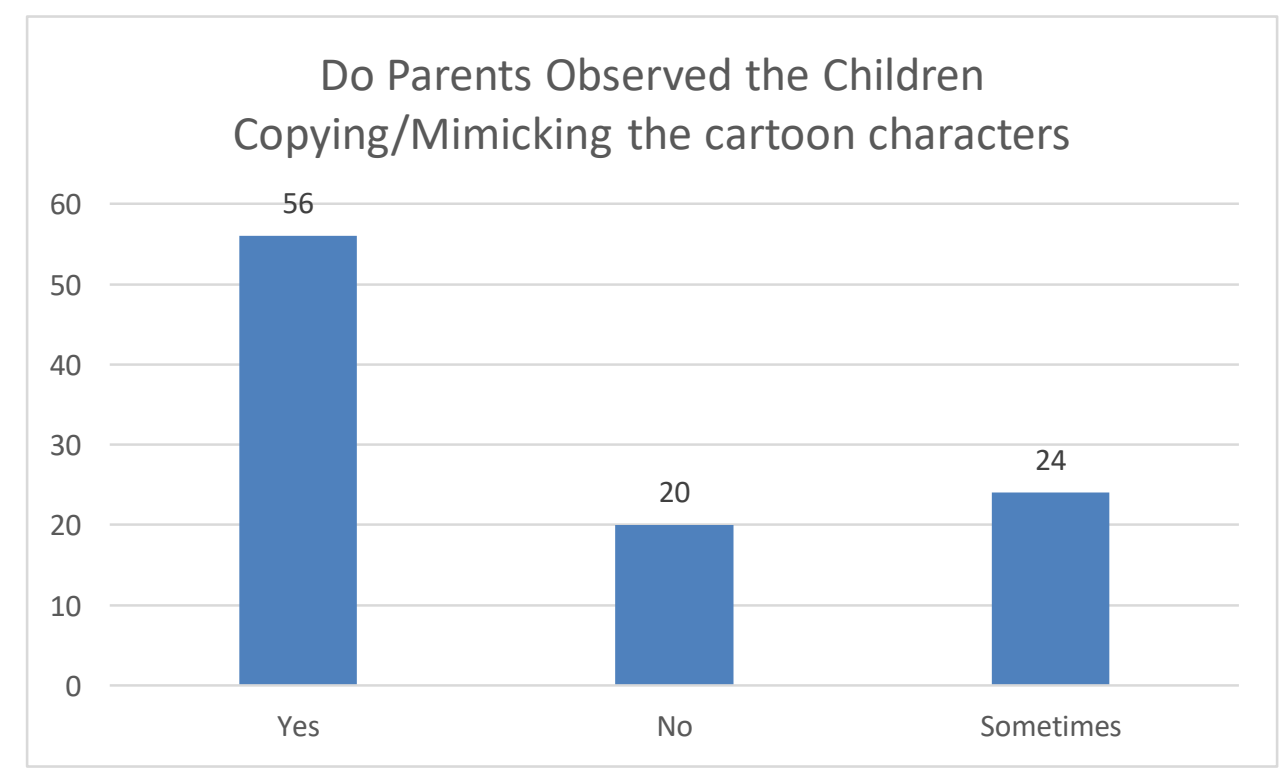

Analysis shows that $56 \%$ of the parents observed their children mimicking /Copying the character they watch in the cartoon shows. While, $24 \%$ of the parents observed it occasionally that their children mimic or copy the cartoon character. On the other hand $20 \%$ parents responded that they have never observed their children mimicking or copying the cartoon characters.

Chart 9: Showing Whether Parents Observed Violence in Behavior of Children after Watching Violent Cartoon Shows 


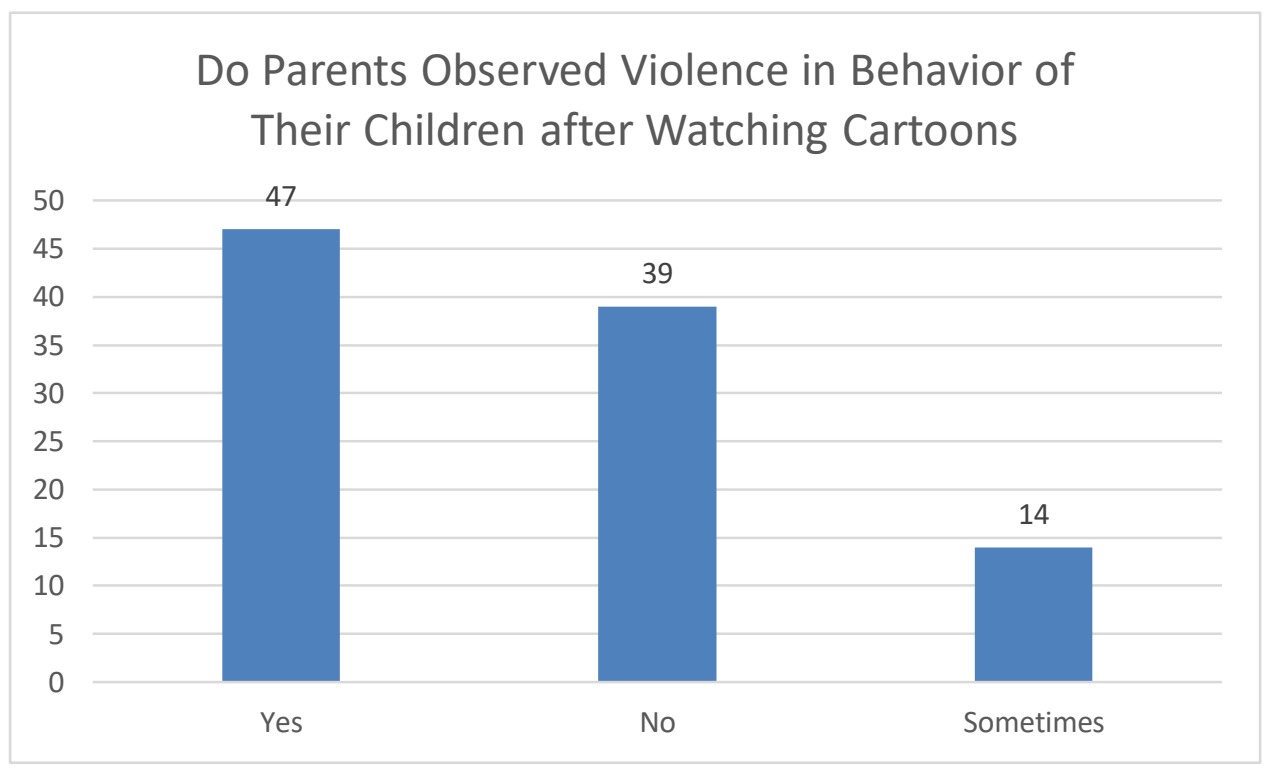

Frequency analysis shows that $47 \%$ of the parents observed violence in the behavior of their children after watching the violent contents in cartoon shows. While, $14 \%$ of the parents observed the violent behaviors occasionally, after watching the violent content in cartoon shows. Among all the parents, $39 \%$ parents did not observed any violent behavior that could be associated to the cartoon viewing.

\section{Conclusion and Discussion}

\section{Test of Research Questions and Hypothesis}

\section{RQ1: Do the cartoons create sense of fear among children.}

Analysis shows that children perceive the content of cartoon shows as actual and they live in a world of fantasy after watching the cartoons. It was observed that $78 \%$ of children feel fear when they go to some dark or alone places after watching horror cartoon shows. On the other hand $14 \%$ of children feel fear only when some situation arises that match the cartoon content (See Chart:6). Only 8\% of children responded that they don not feel any fear after watching the horror cartoon shows. This results clearly maintains that horror cartoon shows cultivate fear among the children.

\section{H1: It is likely to be that violent cartoons makes behaviour of children aggressive.}

The analysis reveals some of the very important results about this hypothesis. $56 \%$ of the children who like fighting/action cartoon, like to fight like their super heroes in real life as well. And $14 \%$ children wants to fight like a super hero, occasionally (See Chart:3). Analysis also shows that $71 \%$ children think that killing, destroying, damaging the enemy is righteous. Among these children, $23 \%$ think that killing, destroying and damaging the enemy is correct in some situations (See Chart:7). Frequency analysis also reveals that $47 \%$ of the parents observed violence in the behavior of their children, who watch violent cartoons (See Chart:9). Analysis also shows that $56 \%$ of the parents observed that their children mimic or Copy the character, they watch in the cartoon shows (See Chart: 8). All these results prove the hypothesis, so $\mathrm{H} 1$ is proved.

\section{H2: It is likely to be that violent cartoons do not lead the children towards immoral acts.}

The analysis reveals that $71 \%$ children, who watch violent cartoons, think that killing, destroying, damaging the enemy is righteous. Among these children, $23 \%$ children are of the opinion that killing, destroying and damaging the enemy is right option but in some special cases. Collectively it makes $94 \%$, who think these types of anti-social actions are legitimized in some way or another. On the other hand only $6 \%$ children believe that killing, destroying or damaging the enemy is not good option in any 
situation (See Chart: 7). the children like fight in cartoon shows (See Chart:1) and they like all kind of fight, wither with latest weapon, bare hands of primitive weapons (See Chart: 2). hence the hypothesis is disproved and $\mathrm{H} 1$ is a Null hypothesis.

\section{Discussion}

The study reveals some of the very important results about the impact of cartoon shows on children. It is observed that children develop fears after watching the cartoons. There is a very significant role of the environment and behavior of the parents in this phenomenon. As the results shows that \% children watch the cartoon alone and $35 \%$ children watch the cartoon when family members are around (See Chart: 4). Additionally, the $76 \%$ of the parents do not guide or counsel the children about the content of the cartoon show (See Chart: 5). It is evident that fear among the children who watch horror cartoon, may not be only due to content. This fear can be due to the environment provided the children for cartoon viewing and due to missing parental guidance.

Children are not competent enough to filter out the bad information. It is the responsibility of the parents to counsel the children and guide them to consume the content of cartoon in a proper way. When this counselling is lacking, then children can learn anti-social behaviour. The results shows that $56 \%$ of the children want to fight like the characters of cartoon shows (See Chart:3). But, 47\% of the parents observed the violent behavior in their children who are exposed to violent cartoon shows (See Chart: 9). so, according to analysis, despite this much higher figure in violent behavior of children, $76 \%$ parents don't guide their children while they watch violent cartoons.

The construction of the cartoon shows and depiction of violence by the "hero" of the cartoon show is also fully responsible for increasing violence and anti-social behavior of children. The "hero" is often depicted as a great warrior, expert in fight and master of weapon. The glorification of violence, destruction and damage caused by the "hero", causes great impact on the developing minds of children and they develop a personality with acceptance of such anti-social activities. The use of modern weapon, bare hands and primitive weapons by the hero, creates liking and acceptance of these weapons/techniques by the children.

\section{Limitations of the Study}

This is primarily is a quantitative study used questioneer. In depth interviews would be more helpful in getting true spirit of the answers. The study was conducted only in the area of Multan, it can be done in larger area to generalize the results.

\section{References}

Anderson, Craig \& Gentile, Douglas \& Buckley, Katherine. (2008). Violent Video Game Effects on Children and Adolescents: Theory, Research, and Public Policy. 10.1093/acprof:oso/9780195309836.001.0001.

Bandura, A., Ross, D. and Ross, S. A. 1963b. Vicarious reinforcement and imitative learning. Journal of Abnormal and Social Psychology,67: 601-607. [Crossref], [Web of Science ${ }^{\circledR}$ ], [Google Scholar]

Clara, J. M., \& Marian, G (1980). The Impact of Television Cartoons on Child Behavior.

Fouts, G., Callan, M., Piasentin, K., Lawson, A. (2006). Demonizing in children's television cartoons and Disney animated films. Child psychiatry \& human development. 37 (1). 15 - 23. DOI 10.1007/s10578-006-0016-7

Gentile, D. A., \& Anderson, C. A. (2006). Violent video games: Effects on youth and public policy implications. Handbook of children, culture, and violence, 225-246.

Ginman, M., Ek, S., Eriksson-Backa, K., Mustonen, M., Torkkola, S., Tuominen, K., \& Wikgren, M. (2003). Health communication and knowledge construction. Health Informatics Journal, 9(4), 301-313.

Greenberg, B. S., \& Reeves, B. (1976). Children and the perceived reality of television. Journal of Social Issues, 32(4), 86-97. 
Gunter, B., \& Gunter, J. (2019). Children and television. Routledge.

Hassan, A., \& Daniyal, M. (2013). Cartoon network and its impact on behavior of school going children: a case study of Bahawalpur, Pakistan. International Journal of Management, Economics and Social Sciences (IJMESS), 2(1), 6-11.

Habib, Khaled \& Soliman, Tarek. (2015). Cartoons' Effect in Changing Children Mental Response and Behavior. Open Journal of Social Sciences. 03. 248-264. 10.4236/jss.2015.39033.

Johnson, J. K. (2014). Super-history: Comic book superheroes and american society, 1938 to the present. McFarland.

Kaye, B. K., \& Sapolsky, B. S. (2004). Watch your mouth! An analysis of profanity uttered by children on prime-time television. Mass Communication \& Society, 7(4), 429-452.

Klein, N. M. (1993). Seven minutes: The life and death of the American animated cartoon. Verso.

Krug et al., "World report on violence and health" Archived 2015-08-22 at the Wayback Machine, World Health Organization, 2002.

Kirsh, Steven J.(2006) "Cartoon violence and aggression in youth." Aggression and Violent Behavior 11, no. 6 (2006): 547-557

Maltin, L., Sader, L., \& Clark, M. (Eds.). (2008). Leonard Maltin's 2009 Movie Guide. Penguin.

Mahsud, M. N., Rawan, B. Y., \& Normn. (2009). The effects of TV cartoon Network on aggressive behavour of school going children. Retrieved 4 4, 2015, from www.aiou.edu. pk: http://www.aiou.edu.pk/gmj/artical6(Aut-08).asp

Merriam-Webster. (n.d.). Violence. In Merriam-Webster.com dictionary. Retrieved June 13, 2020, from https://www.merriam-webster.com/dictionary/violence

Nair, A (2018). Positive and Negative Effects of Cartoons on Child Behaviour and Development Retrieved on June 13, 2020, from https://parenting. firstcry. com/article s /positive- and-negativeeffects- of-cartoons -on-child -behaviour -and- development/

Raza, S., Awan, S., \& Gondal, S. (2016). What are Your Children Watching? Teacher's Evaluation of the Educational, Emotional, Behavioral, Psychological, Physical \& Religious Impacts of Cartoons on the School Going Children. Teacher's Evaluation of the Educational, Emotional, Behavioral, Psychological, Physical \& Religious Impacts of Cartoons on the School Going Children, 39-45.

Raza, S.H., Abu Bakar, H. and Mohamad, B. (2019). The effects of advertising appeals on consumers' behavioural intention towards global brands: The mediating role of attitude and the moderating role of uncertainty avoidance, Journal of Islamic Marketing, 11(2), 440-460. https://doi.org/10.1108/JIMA-11-2017-0134

Raza, Syed Hassan, Hassan Abu Bakar, and Bahtiar Mohamad. "Advertising appeals and Malaysian culture norms: Scale content validation." Journal of Asian Pacific Communication 28, no. 1 (2018): 61-82

Seck, M. M. (2007). Psychosocial Characteristics of Violent Juvenile Offenders with Serious Mental/behavioral Disorders (Doctoral dissertation, Case Western Reserve University).

Shaffer, D. R., \& Kipp, K. (2007). Developmental psychology: Childhood and adolescence. Australia: Wadsworth/Thomson.

Scharrer, E. (2006). " I Noticed More Violence:" The Effects of a Media Literacy Program on Critical Attitudes Toward Media Violence. Journal of Mass Media Ethics, 21(1), 69-86.

Velikovsky, J. T. (2012). Animation and narrative in videogames: A case study-Looney Tunes: Acme Arsenal. Animation Practice, Process \& Production, 2(1-2), 11-48. 